\title{
Preconceito e discriminação sofridos por pessoas transgênero em serviços de saúde: Revisão integrativa da literatura
}

\author{
Prejudice and discrimination suffered by transgender persons in health services: Integrative
}

\section{literature review}

Los prejuicios y la discriminación que sufren las personas trans en los servicios de salud: Revisión

\section{integradora de la literatura}

ORCID: https://orcid.org/0000-0002-0803-506X Centro Universitário Metropolitano da Amazônia, Brasil E-mail: marcioalves22@hotmail.com

Brenda Tanielle Dutra Barros

ORCID: https://orcid.org/0000-0002-3184-050X Centro Universitário Metropolitano da Amazônia, Brasil E-mail: brendatanielle.enf@gmail.com

Rômulo Leno Miranda Barros ORCID: https://orcid.org/0000-0003-1802-4521 Universidade da Amazônia, Brasil E-mail: romuloleno@ hotmail.com

Tatiana Fabíola da Silva Lima ORCID: https://orcid.org/0000-0001-5966-9727 Centro Universitário Metropolitano da Amazônia, Brasil E-mail: tatiana.fs.lima2@gmail.com

Virgínia Mercês Lara Pessoa Oliveira

ORCID: https://orcid.org/0000-0002-4417-637X Centro Universitário Metropolitano da Amazônia, Brasil E-mail: virginiaoliveira@ famaz.edu.br Catarina Santos Ramos

ORCID: https://orcid.org/0000-0002-2376-8333 Centro Universitário Metropolitano da Amazônia, Brasil E-mail: catramosblue@gmail.com

José Eduardo Resende Campos

ORCID: https://orcid.org/0000-0002-4070-8543 Centro Universitário Metropolitano da Amazônia, Brasil E-mail: educamposjrc@gmail.com

Luceny Oliveira Mendes

ORCID: https://orcid.org/0000-0003-0505-9493 Centro Universitário Metropolitano da Amazônia, Brasil E-mail: lumemetais08@hotmail.com

Elder Mescouto de Brito

ORCID: https://orcid.org/0000-0001-7246-2309 Centro Universitário Metropolitano da Amazônia, Brasil E-mail: eldermescouto@outlook.com

Mayra Gama Leão Pereira

ORCID: https://orcid.org/0000-0002-1050-4590 Universidade Federal do Pará, Brasil E-mail: mayra_leao@live.com 


\author{
Katielem Melo Vale \\ ORCID: https://orcid.org/0000-0003-4868-1223 \\ Centro Universitário Metropolitano da Amazônia, Brasil \\ E-mail: katielem.enf@gmail.com \\ Ana Mara Franco Almeida Couto \\ ORCID: https://orcid.org/0000-0003-2871-6134 \\ Faculdade Paraense de Ensino, Brasil \\ E-mail: maraanafranco@gmail.com
}

\begin{abstract}
Resumo
Embora alguns avanços tenham se apresentado nos últimos anos, estudos mostram que os serviços de saúde tendem a se organizar para uma clientela heterossexual, limitando suas possibilidades de atuação efetiva junto a pacientes transgênero. Este estudo teve como objetivo descrever as evidências científicas sobre o preconceito e a discriminação sofridos por pessoas transgênero em serviços de saúde. Trata-se de um estudo de revisão integrativa da literatura. As bases de dados pesquisadas foram BVS, LILACS, SCIELO, MEDLINE e BDENF. Definiu-se o período dos artigos publicados de 2011 a 2020. Para extração dos dados foi utilizado o formulário de Ursi \& Galvão e para análise dos dados, o sistema de classificação de evidências, adotando-se a hierarquia das evidências, em relação ao delineamento de pesquisa. A amostra do estudo foi constituída por sete artigos originais. Os resultados foram expostos e discutidos em duas categorias temáticas: Acesso à rede de saúde e os tipos de preconceitos e discriminações sofridos por pessoas transgêneros e A assistência de enfermagem perante as políticas voltadas ao público LGBTQIA+. O atendimento discriminatório e as condutas constrangedoras estão entre as principais causas desta população se afastarem dos serviços de saúde, se automedicarem e não adotarem cuidados preventivos. Concluiu-se que o maior papel da enfermagem para as pessoas LGBTQI+ é a garantia de uma assistência digna e humanizada desde o setor básico de saúde até o de alta complexidade, tornando-se fundamental para promoção de saúde integral, qualificada, humanizada, favorecendo a cidadania.
\end{abstract}

Palavras-chave: Pessoas transgênero; Questões de gênero; Enfermagem; Serviços de saúde; Sistema único de saúde.

\begin{abstract}
Although some advances have been made in recent years, studies show that health services tend to organize for a heterosexual clientele, limiting their possibilities of effective action with transgender patients. This study aimed to describe the scientific evidence on the prejudice and discrimination suffered by transgender people in health services. This is an integrative literature review study. The databases searched were BVS, LILACS, SCIELO, MEDLINE and BDENF. The period of articles published from 2011 to 2020 was defined. For data extraction, the Ursi \& Galvão form was used and for data analysis, the evidence classification system, adopting the evidence hierarchy, in relation to the outline of research. The study sample consisted of seven original articles. The results were exposed and discussed in two thematic categories: Access to the health network and the types of prejudices and discrimination suffered by transgender people and Nursing care in the face of policies aimed at the LGBTQI+ public. Discriminatory care and embarrassing behaviors are among the main causes of this population to withdraw from health services, self-medicate and not adopt preventive care. It was concluded that the greatest role of nursing for LGBTQIA+ people is the guarantee of dignified and humanized assistance from the basic health sector to the high complexity sector, becoming essential for the promotion of comprehensive, qualified, humanized health, favoring the citizenship.
\end{abstract}

Keywords: Transgender people; Gender issues; Nursing; Health services; Health unic system.

\title{
Resumen
}

Aunque se han logrado algunos avances en los últimos años, los estudios muestran que los servicios de salud tienden a organizarse para una clientela heterosexual, lo que limita sus posibilidades de acción efectiva con pacientes transgénero. Este estudio tuvo como objetivo describir la evidencia científica sobre el prejuicio y la discriminación que sufren las personas trans en los servicios de salud. Este es un estudio de revisión de literatura integradora. Las bases de datos buscadas fueron BVS, LILACS, SCIELO, MEDLINE y BDENF. Definiu-se o período dos artigos publicados de 2011 a 2020. Para extração dos dados foi utilizado o formulário de Ursi \& Galvão e para análise dos dados, o sistema de classificação de evidências, adotando-se a hierarquia das evidências, em relação ao delineamento de búsqueda. La muestra de estudio estuvo formada por siete artículos originales. Los resultados fueron expuestos y discutidos en dos categorías temáticas: Acceso a la red de salud y los tipos de prejuicios y discriminación que sufren las personas trans y Atención de enfermería frente a políticas dirigidas al público LGBTQI+. Los cuidados discriminatorios y las conductas vergonzosas se encuentran entre las principales causas de que esta población se retire de los servicios de salud, se automedique y no adopte cuidados preventivos. Se concluyó que el mayor rol de la enfermería para las personas LGBTQI+ es la garantía de una asistencia digna y humanizada desde el sector básico de la salud al sector de alta complejidad, tornándose fundamental para la promoción de la salud integral, calificada, humanizada, favoreciendo la ciudadanía.

Palabras clave: Personas transgénero; Cuestiones de género; Enfermería; Servicios de salud; Sistema único de salud. 


\section{Introdução}

Pessoas Lésbicas, Gays, Bissexuais, Transexuais/Travestis/Transgêneros, Queer, Intersexuais (LGBTQI+) sofrem preconceitos por parte da sociedade desde a antiguidade, mas essa questão se agravou durante década de 1980, quando foi descoberto o Vírus da Imunodeficiência Humana (HIV), o que estava atrelado às práticas sexuais diversas, e os indivíduos LGBTQI+ foram taxados como as pessoas que cometiam atos errôneos e passíveis de repreensão, com seu próprio corpo e, a partir deste momento, a homossexualidade foi vista como o principal disseminador do HIV, assim, o período foi marcado pela disseminação de ideias negativas e discriminatórias sobre esta população (Cardoso, 2012).

A expressão do gênero pode ocorrer de maneiras variadas, como masculino, feminino (em que há traços e comportamentos de gênero precisos). Existe também a denominação de gênero fluído, em que o indivíduo polariza pelo feminino e masculino em momentos alternados do seu cotidiano. Pessoas transgênero podem se auto identificar como mulher transgênero, mulher trans ou homem transgênero ou trans e, ainda, transexual, ou por uma variedade de termos culturais específicos ao tempo e espaço (Jesus, 2012).

Os transgêneros, incluindo travestis e transexuais, estão entre a camada da população que acabam estando mais suscetíveis à discriminações e outros tipos de violências. São detentores de identidades de gênero distintas às padronizadas pelo héteronormativismo presente na sociedade. Essa população vivencia a lógica hegemônica de sexo biológico como fator que determina a identidade de gênero e, desta forma, qualquer um que fuja da lógica binária e dicotômica, são tidos como estranhos (Popadiuk et al., 2017).

O primeiro programa lançado para a população LGBTQI+ foi o "Programa Brasil sem Homofobia", que surgiu em 2004, desenvolvido pela Secretaria de Direitos Humanos da Presidência da República, com o objetivo de combater as formas de preconceito e discriminação, por meio da consolidação de políticas públicas para a promoção da cidadania da população LGBT, e foi considerado avanço na história da conquista dos direitos cidadãos brasileiros. Após a criação do programa, ocorreram duas Conferências Nacionais dos Direitos LGBT, entre 2008 e 2011. Em 2009, foi lançado o I Plano Nacional de Promoção dos Direitos LGBT e dois anos após foi criado o Conselho Nacional dos Direitos LGBT. Já em 2013, surgiu o Sistema Nacional de Enfrentamento à Violência Contra LGBT e Promoção de Direitos (Querino et al., 2017).

Historicamente e, em especial, durante a consolidação do Sistema Único de Saúde (SUS), percebe-se o grande desafio que os trabalhadores da saúde enfrentam para romper o preconceito enraizado frente à diversidade sexual. Tal dificuldade está intimamente relacionada à sociedade que estipula um padrão de normalidade (heterossexual) a ser seguido, rejeitando quem não se enquadra nesse perfil idealizado. Diante disso, nota-se a importância de se ter formação sólida e atualizada, que prepare a enfermagem para conhecer as reais necessidades dessa parcela da população, objetivando o cuidado humanizado e compatível com os princípios idealizados pelo SUS, de forma universal, integral e com equidade (Brasil, 2013).

O enfermeiro deve realizar ações junto ao grupo LGBTQI+, proporcionando informações inerentes à Infecções Sexualmente Transmissíveis (IST), prevenção de casos de câncer de próstata e de colo de útero, favorecer a garantia dos direitos reprodutivos integrais e também atuar nas ações que visam a redução do índice de suicídios por depressão e outras causas nesses clientes, cuidando de forma humanizada e especializada dentro das Unidades Básicas de Saúde (UBS), serviços de urgência e emergência e outros do SUS. Assim, o papel fundamental da enfermagem para o público LGBTQI+ é a garantia um cuidado digno e humanizado, pautado em ações fundamentalmente voltadas para a promoção da saúde integral, com medidas efetivas e qualificadas (Querino, et al., 2017).

Vivencia-se em um período extremamente importante no que se refere a aceitação da diversidade social e cultural em que estamos inseridos. Assim, no Art. 3º, Inciso IV, da Constituição Federal Brasileira de 1988, as pessoas não podem sofrer nenhum tipo de discriminação. Deste modo, faz-se de grande necessidade incentivar ações de conscientização, sensibilização, esclarecimento e aceitação da diversidade humana, incluindo aquelas associadas à sexualidade. Desta forma, a 
enfermagem tem papel importante, desde a questão de educação em saúde, a assistencial, e a participação na construção das políticas públicas de saúde que tem por objetivo favorecer a aplicação dos princípios do SUS, junto a esse público (Brasil, 2013).

Esta questão vai além do campo da saúde, pois envereda pelo histórico social da população, surgem demandas e necessidades de ação, as quais partem impulsionadas pelo sentimento de revolta, busca por mudanças e, sobretudo, o desejo de igualdade ou melhor, equidade. Estudos sobre a diversidade são contundentes ao mostrar que os grupos LGBTQI+, especialmente nos últimos 30 anos, passam a criar movimentos em prol dos direitos da sua orientação sexual e identidade de gênero e, a partir dessa iniciativa erguem-se então, divergências, debates nos diversos campos, incluindo o da saúde e inevitavelmente, a necessidade em definir "um ser" o qual com sua identidade possa ocupar seu espaço na sociedade sem apontamentos quanto a sua orientação sexual (Querino et al., 2017).

A relevância desta pesquisa se traduz em abordar um tema ainda sensível na sociedade assim como, trazer a debate a histórica estigmatização, marginalização, preconceito e discriminação impostas à população transgênero, por não se alinhar aos padrões impostos como normais e tradicionais acerca da identidade de gênero. Vale ressaltar que todo o tipo de violência sofrida por esta população são constantes, ocorrendo de modo escancarado ou velado, pois também violentam-se os indivíduos ao excluí-los do meio social, interferindo em seu acesso aos serviços, incluindo os de saúde, e sequer reconhecendo sua identidade de gênero (Jesus, 2012).

Desta forma, considerando todo este contexto, questionou-se: Quais as abordagens da produção científica referente ao preconceito e a discriminação sofridos por pessoas transgêneros em serviços de saúde?

\section{Metodologia}

Esta Revisão Integrativa da Literatura (RIL) caracteriza-se como um estudo descritivo, apresentando uma abordagem qualitativa. A revisão integrativa está presente proporciona a síntese/análise das pesquisas, gerando uma e ampliação sobre a visualização dos artigos já publicados, fundamentando-se nos mais diversos saberes. Já a abordagem qualitativa fornece análise de casos em função de um período de tempo previamente determinado e localização e se apresenta através de significados queos indivíduos dão a suas experiências e vivências (Minayo, 2017; Lima et al., 2021).

Foi desenvolvida no período de julho a outubro de 2020, sendo seguidas as seis fases do processo de elaboração de uma Revisão Integrativa de Literatura: $1^{\circ}$ Etapa - identificação/ seleção da hipótese ou questão de pesquisa; $2^{\circ}$ Etapa - Procura e seleção de uma evidência plausível; $3^{\circ}$ Etapa - Avaliação crítica das evidências; $4^{\circ}$ Etapa - Integração das evidências; $5^{\circ}$ Etapa - discussão dos resultados obtidos; $6^{\circ}$ Etapa - apresentação da síntese dos conhecimentos produzidos; revisão/síntese do conhecimento (Teixeira et al., 2014; Botelho, Cunha \& Macedo, 2011).

A primeira fase ocorreu a partir da elaboração da questão norteadora junto a escolha das bases de dados e das palavras-chave. A questão norteadora pautou-se em: Quais as abordagens da produção científica referente ao preconceito e a discriminação sofridos por pessoas transgêneros em serviços de saúde evidenciados na literatura no período de 2011 a 2020 ?

A busca ocorreu nas bases de dados Literatura Latino-Americana e do Caribe em Ciências da Saúde (LILACS), Medical Literature Analysis and Retrieval System (MEDLINE), Base de dados de Enfermagem (BDENF) e Scientifc Electronic Library Online (SciELO).

Como palavras-chave, foram utilizados: "Pessoas transgênero", "Questões de gênero", "Enfermagem", "Serviços de saúde" e "Sistema Único de Saúde", com a utilização dos operadores booleanos "and"; "or" para os cruzamentos de palavras.

A terceira fase ocorreu a partir da seleção dos estudos primários, conforme os critérios de inclusão, foram pautados conforme os seguintes pontos: artigos originais, em língua portuguesa, espanhola ou inglesa, disponíveis na íntegra, com acesso gratuito, que abordassem sobre a questão norteadora, publicados no recorte temporal entre de 2011 a 2020. 
Como critérios de exclusão: artigos de acesso pago, monografias, dissertações, teses, artigos de revisão, artigos de opinião e artigos em que o desfecho não contemplace os objetivos desta pesquisa.

Na terceira fase da extração de dados, foi utilizado o formulário Ursi \& Galvão (2005) para coleta de dados relevantes ao estudo. Na quarta fase foi realizado a análise crítica dos estudos aplicando o sistema de classificação de evidências, adotando-se a hierarquia das evidências, em relação ao delineamento de pesquisa. Neste estudo a principal evidência foi de nível 4: Evidências de estudo não-experimental ou com abordagem qualitativa.

Nesta quinta fase, apresentam-se os resultados da pesquisa, onde as principais evidências foram sintetizadas em quadros sínteses para encontrar os nexos entre os artigos pesquisados encontrando resposta a nossa questão de pesquisa e objetivos propostos, após foi comparado ao referencial teórico que fundamentou o estudo.

E na sexta fase foi elaborada e apresentada a descrição dos resultados encontrados no estudo a partir das seguintes categorias temáticas: 1) Acesso a rede de saúde e os tipos de preconceitos e discriminações sofridos por pessoas transgênero; e 2) A assistência de enfermagem perante as políticas voltadas ao público LGBTQI+.

Os objetivos dos estudos que compuseram esta revisão foram estudados, e seus achados explorados para possibilitar a análise das abordagens da produção científica referente ao preconceito e a discriminação sofridos por pessoas transgênero em serviços de saúde.

\section{Resultados}

Foram identificadas, a princípio somando-se todas as bases pesquisadas, um total de 1.011 evidências científicas. Obteve-se um resultado de 11 estudos. Após a leitura de modo pormenorizado dos artigos completos, identificou-se que 7 destes possuíam relação direta com o tema objeto e com a questão da pesquisa;

Utilizou-se o fluxograma (PRISMA) para apresentação da disposição dos resultados, conforme disposto a seguir: 
Fluxograma 1: Fluxograma PRISMA dispondo as etapas de inclusão dos artigos
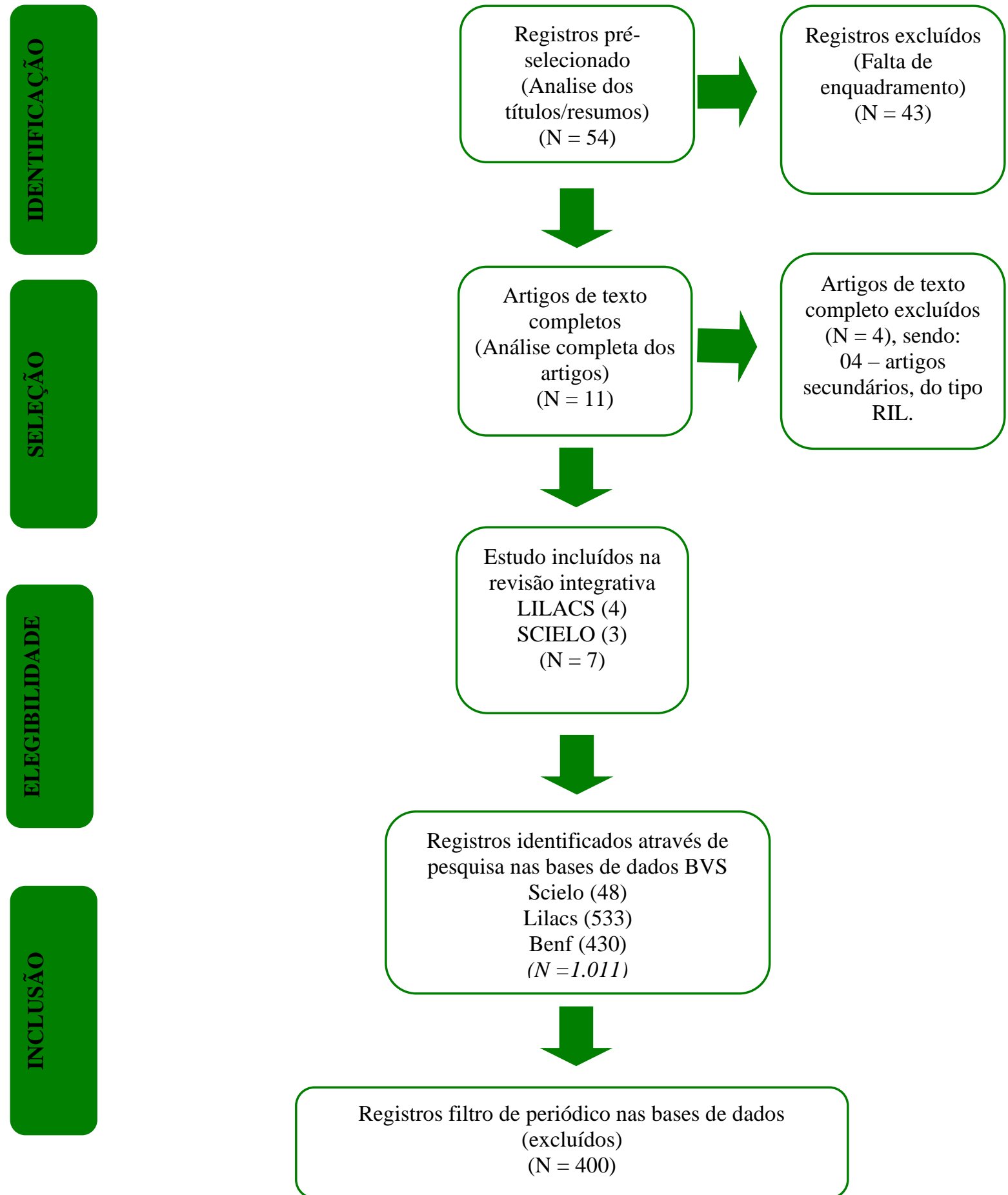

Fonte: Adaptado de Moher et al., (2009)

A partir da análise dos estudos postos no Fluxograma 1 e da identificação amostral de 7 (sete) artigos selecionados, os estudos foram agrupados e expostos em quadros-síntese, onde foi utilizado o instrumento adaptado de Ursi e Galvão (2015). Selecionou-se os intens: Código (Abrev.: Cód.); Título; Autores; Base de dados e Ano, para o Quadro-síntese 1 e Código (Abrev.: Cód.); Periódico científico; Objetivo; Síntese dos resultados e Nível de evidência para o Quadro-síntese 2. 
Quadro-síntese 1: Caracterização dos artigos.

\begin{tabular}{|c|l|l|c|c|}
\hline CÓD. & \multicolumn{1}{|c|}{ TÍTULO } & \multicolumn{1}{|c|}{ AUTORES } & BASE DE DADOS & ANO \\
\hline 1 & $\begin{array}{l}\text { Diversidade sexual e homofobia: o conhecimento de } \\
\text { enfermeiros da estratégia saúde da família }\end{array}$ & $\begin{array}{l}\text { ROMEIKA, G. W. } \\
\text { S.S. et al. }\end{array}$ & LILACS & 2016 \\
\hline 2 & $\begin{array}{l}\text { O cotidiano de enfermeiras e enfermeiros: relações de } \\
\text { gênero, a partir do tempo no hospital. }\end{array}$ & $\begin{array}{l}\text { PEREIRA VIDAL, } \\
\text { Audrey }\end{array}$ & LILACS & 2015 \\
\hline 3 & $\begin{array}{l}\text { Travestis e transexuais: despindo as percepções acerca } \\
\text { do acesso e assistência em saúde }\end{array}$ & LOVISON, R. et al. & LILACS & 2019 \\
\hline 4 & $\begin{array}{l}\text { Assistência de enfermagem às mulheres lésbicas e } \\
\text { bissexuais }\end{array}$ & $\begin{array}{l}\text { CABRAL, T.F.K. et } \\
\text { al. }\end{array}$ & LILACS & 2019 \\
\hline 5 & $\begin{array}{l}\text { A construção epistemológica da transexualidade: a } \\
\text { ciência, enfermagem e o senso comum }\end{array}$ & JANINI, P. J., et al & SCIELO & 2019 \\
\hline 6 & $\begin{array}{l}\text { Gênero e cuidados em saúde: Concepç̃̃es de } \\
\text { profissionais que atuam no contexto ambulatorial e } \\
\text { hospitalar }\end{array}$ & JÚNIOR, C. M. et al. & SCIELO & 2016 \\
\hline 7 & $\begin{array}{l}\text { Oacesso ao Sistema Único de Saúde na percepção de } \\
\text { homossexuais masculinos }\end{array}$ & $\begin{array}{l}\text { SANTOS, S. E. L. et } \\
\text { al. }\end{array}$ & SCIELO & 2019 \\
\hline
\end{tabular}

Fonte: Pesquisa dos autores.

Quadro-síntese 2: Contribuições dos estudos.

\begin{tabular}{|c|c|c|c|c|}
\hline CÓD. & $\begin{array}{l}\text { PERIÓDICO } \\
\text { CIENTÍFICO }\end{array}$ & OBJETIVO & SÍNTESE DOS RESULTADOS & $\begin{array}{c}\text { NÍVEL DE } \\
\text { EVIDÊNCIA }\end{array}$ \\
\hline 1 & $\begin{array}{c}\text { Revista de } \\
\text { pesquisas e } \\
\text { cuidados } \\
\text { ONLINE }\end{array}$ & $\begin{array}{l}\text { Objetiva-se analisar o } \\
\text { conhecimento de } \\
\text { enfermeiros da Estratégia } \\
\text { Saúde da Família no } \\
\text { tocante à diversidade sexual } \\
\text { e à homofobia }\end{array}$ & $\begin{array}{l}\text { Os enfermeiros relatam a diversidade sexual como sistema de } \\
\text { orientação sexual e sexo biológico. Sobre homofobia, } \\
\text { atribuíram significados coerentes. No entanto, atenta-se para } \\
\text { a expressão da "homofobia implícita" ou "simbólica". Faz-se } \\
\text { urgente a promoção da saúde através do reconhecimento das } \\
\text { determinantes sociais, pois, a vivência e a aproximação com a } \\
\text { multiplicidade sexual existente na área de adstrição de } \\
\text { enfermeiros pode ser apresentada como forma de } \\
\text { enfrentamento às questões relativas à diversidade sexual. }\end{array}$ & NÍVEL 4 \\
\hline 2 & $\begin{array}{l}\text { Rev. Latino- } \\
\text { Am. } \\
\text { Enfermagem }\end{array}$ & $\begin{array}{l}\text { Analisar os tempos da vida } \\
\text { cotidiana de enfermeiras e } \\
\text { enfermeiros, através da } \\
\text { divisão sexual do trabalho e } \\
\text { das relações de } \\
\text { interdependência, a partir } \\
\text { do tempo no hospital. }\end{array}$ & $\begin{array}{l}\text { Os registros dos tempos permitiram observar diferenças entre } \\
\text { os grupos estudados, sendo úteis para identificação de } \\
\text { conflitos, tensões, disputas de poder e desigualdades de } \\
\text { gênero nas relações cotidianas das(os) entrevistadas(os), que } \\
\text { afetam não apenas a saúde física e mental, mas os modos de } \\
\text { vida. O percurso analítico apontou a necessidade de políticas } \\
\text { públicas que promovam equidade nas relações de gênero, } \\
\text { com vistas ao exercício de posturas tolerantes e discursos } \\
\text { plurais capazes de respeitar as diferenças entre os tempos } \\
\text { individuais e coletivos. }\end{array}$ & NÍVEL 4 \\
\hline 3 & $\begin{array}{c}\text { Revista } \\
\text { Enfermagem } \\
\text { Foco }\end{array}$ & $\begin{array}{l}\text { Conhecer a percepção de } \\
\text { travestis e transexuais } \\
\text { residentes em Chapecó, } \\
\text { Santa Catarina, acerca do } \\
\text { acesso e assistência em } \\
\text { saúde. }\end{array}$ & $\begin{array}{l}\text { Estudo revelou que a discriminação a travestis e transexuais } \\
\text { ainda ocorre e se revela especialmente no não } \\
\text { reconhecimento ao nome social. Conclusão: a conduta de } \\
\text { acesso e acolhimento não atende aos critérios de acesso e } \\
\text { assistência em saúde preconizados pelo Sistema Único de } \\
\text { Saúde. A Enfermagem tem papel fundamental na construção } \\
\text { de uma nova cultura de acolhimento, em que a discriminação } \\
\text { e o preconceito sejam banidos das práticas de acesso e } \\
\text { assistência em saúde. }\end{array}$ & NÍVEL 4 \\
\hline 4 & $\begin{array}{l}\text { Assistência de } \\
\text { enfermagem às } \\
\text { mulheres } \\
\text { lésbicas e } \\
\text { bissexuais }\end{array}$ & $\begin{array}{c}\text { Analisar, sob a ótica de } \\
\text { mulheres lésbicas e } \\
\text { bissexuais, a assistência de } \\
\text { Enfermagem em Unidades } \\
\text { de Saúde da Família. }\end{array}$ & $\begin{array}{l}\text { Constataram-se as dificuldades enfrentadas pelas mulheres } \\
\text { lésbicas e bissexuais durante a consulta de Enfermagem tais } \\
\text { como a falta de acolhimento, o preconceito e as informações } \\
\text { inespecíficas sobre a prevenção de doenças. Conclusão: } \\
\text { evidenciou-se que as mulheres não foram acolhidas, cuidadas } \\
\text { e assistidas quanto às suas necessidades de saúde e } \\
\text { especificidades. Conclui-se que é preocupante a falta de }\end{array}$ & NÍVEL 4 \\
\hline
\end{tabular}




\begin{tabular}{|c|c|c|c|c|}
\hline & & & $\begin{array}{l}\text { assistência dos profissionais de Enfermagem em relação às } \\
\text { questões das especificidades das mulheres lésbicas e } \\
\text { bissexuais. Descritores: Homossexualidade Feminina; } \\
\text { Atenção Primária à Saúde; Cuidados de Enfermagem; } \\
\text { Minorias Sexuais e de Gênero; Preconceito; Acolhimento. }\end{array}$ & \\
\hline 5 & $\begin{array}{l}\text { Revista Esc } \\
\text { Anna Nery }\end{array}$ & $\begin{array}{l}\text { Conhecer o senso comum } \\
\text { de mulheres transexuais em } \\
\text { reação ao processo } \\
\text { transexualizador e discutir a } \\
\text { construção epistemológica } \\
\text { acerca da transexualidade e } \\
\text { da enfermagem nesse } \\
\text { processo }\end{array}$ & $\begin{array}{l}\text { A construção epistemológica da transexualidade, se dá por } \\
\text { meio da ciência, que instrumentalizou a Política do Processo } \\
\text { Transexualizador e não dispõe de conhecimento apresentado } \\
\text { pelo senso comum das usuárias. A ciência tem um papel de } \\
\text { criar ordem e práticas a partir do refinamento do senso } \\
\text { comum, mas não utiliza o senso comum das mulheres } \\
\text { transexuais na construção epistemológica da transexualidade, } \\
\text { que compromete a assistência e reforça o caráter } \\
\text { estereotipado e patológico pelos profissionais de saúde. A } \\
\text { ciência tem o poder de validar o senso comum, sedimentando } \\
\text { a assistência às mulheres transexuais, em especial, a prática } \\
\text { de enfermagem. A enfermagem tem o desafio de } \\
\text { compreender as questões relacionadas à transexualidade } \\
\text { articulando o senso comum com o saber científico. }\end{array}$ & NÍVEL 4 \\
\hline 6 & $\begin{array}{c}\text { Revista Latino- } \\
\text { Americana }\end{array}$ & $\begin{array}{c}\text { Fomentar este debate } \\
\text { possibilita promover o } \\
\text { reconhecimento das } \\
\text { desigualdades de gênero e } \\
\text { viabilizar estratégias de } \\
\text { formação continuada que } \\
\text { visem garantir a equidade e } \\
\text { a integralidade nos } \\
\text { diferentes níveis de atenção } \\
\text { em saúde. }\end{array}$ & $\begin{array}{l}\text { Discutem-se diferenças nos cuidados com a saúde em função } \\
\text { do gênero e o atendimento prestado em relação ao gênero. Os } \\
\text { profissionais relatam diferenças no atendimento e nas atitudes } \\
\text { de pacientes homens e mulheres nos serviços de saúde; que } \\
\text { eles atribuem a fatores biológicos e sociais. Conclui-se que } \\
\text { questões de gênero estão presentes na atuação dos } \\
\text { profissionais de saúde e devem ser consideradas na sua } \\
\text { formação }\end{array}$ & NÍVEL 4 \\
\hline 7 & $\begin{array}{c}\text { Revista } \\
\text { Brasileira de } \\
\text { Enfermagem }\end{array}$ & $\begin{array}{l}\text { Analisar a percepção de } \\
\text { homossexuais masculinos a } \\
\text { respeito do acesso ao } \\
\text { Sistema Único de Saúde. }\end{array}$ & $\begin{array}{l}\text { Análise revelou cinco categorias temáticas que expressam as } \\
\text { limitações na humanização e no acolhimento, bem como na } \\
\text { qualidade do atendimento à saúde oferecido aos sujeitos, } \\
\text { desconsiderando as demandas psicossociais e relacionadas ao } \\
\text { estilo de vida. Destaca-se que a técnica do grupo focal } \\
\text { contribuiu para a aproximação da pesquisa com a percepção } \\
\text { dos homossexuais masculinos marcada por preconceito e } \\
\text { discriminação, refletindo a insatisfação dos sujeitos com o } \\
\text { atendimento recebido nos serviços de saúde. }\end{array}$ & NÍVEL 4 \\
\hline
\end{tabular}

Fonte: Pesquisa dos autores.

Após análise dos Quadros-sínteses 1 e 2, identificou-se duas categorias temáticas: Acesso a rede de saúde e os tipos de preconceitos e discriminações sofridos por pessoas transgênero e A assistência de enfermagem perante as políticas voltadas ao público LGBTQI+.

\section{Categoria 1: Acesso a rede de saúde e os tipos de preconceitos e discriminações sofridos por pessoas transgênero.}

Embora sejam reconhecidos os avanços relativos aos direitos do grupo LGBTQI+ e o acesso à saúde ser direito fundamental do ser humano e dever do Estado, o que se observa é que a implementação de ações que favoreçam a materialização de um padrão assistencial específico, humano e eficiente ainda se mostra um grande desafio no âmbito do SUS, especialmente quanto a garantir abrangência ao público de lésbicas, gays, bissexuais, travestis, transexuais e as outras variações da significação de gênero. Atualmente, ainda se fazem presentes manifestações de homofobia, transfobia e o preconceito dentro sociedade brasileira, que também está presente nos serviços de saúde, sustentando e agravando o deficitário atendimento a ser ofertado no SUS, indo na contramão das políticas de cuidado humanizado preconizados dentro desse sistema (Lovison et al., 2020).

Atualmente a relação estabelecida entre homossexualidade e outras formas de expressão de gênero e assistência à saúde tem sido discutida com frequência, passando a ser motivo de debates e contestações tanto no campo das ciências 
médicas quanto nas ciências sociais. Tal discussão se concentra, sobretudo ao acesso da população LGBTQI+ aos serviços saúde, pois o mesmo é marcado por obstáculos, como condutas inadequadas, julgamentos pessoais, ofensas verbais e atendimento discriminatório, vindos inclusive dos profissionais de saúde; sendo condutas reprováveis e que acabam por afastar esse público dos serviços assistenciais (Santos et al., 2020).

Cabral et al. (2019) expõe que em meados do século XX surgiram movimentos sociais reivindicando a criação de políticas públicas para uma maior visibilidade de mulheres lésbicas e bissexuais que procuravam o serviço de saúde, pois nesta busca por atendimento tais mulheres enfrentam vários obstáculos, que envolve desde a invisibilidade da sexualidade até o preconceito.

Foi evidenciado nas pesquisas de Dourado et al. (2017), as falas de pessoas travestis e mulheres transexuais sobre a falta de compreensão e o estampado preconceito advindos de trabalhadores da saúde no atendimento e realização de procedimentos a esta população. Pinto et al., (2017) ressalta que, de cada cinco pessoas transexuais e travestis, ao menos uma relatou ter sofrido discriminação, explícita ou velada, nos serviços de saúde nos últimos anos.

Para Santos et al. (2016), tanto no âmbito da saúde como na educação o preconceito e a discriminação provocam carência de direitos, sejam reprodutivos ou sociais, dessa forma a lesbofobia, homofobia ou transfobia materializam-se em muitos dos casos de forma violenta, seja física, verbal ou cultural tanto contra pessoas que relacionam-se com indivíduos do mesmo sexo quanto na forma de retaliação a heterossexuais, que expressam solidariedade e/ou afetividade fraternal com o grupo LGBTQI+.

É relevante considerar que o contexto discriminador tem relação com o forte tabu sociocultural acerca do tema sexualidade, que está enraizado na sociedade e na família e vem perpassando apelas várias gerações, o que influência diretamente sobre o entendimento e conduta dos profissionais da saúde e, de fato, interfere no contexto da assistência à saúde dos indivíduos que, sob esses olhares, "fogem às regras e padrões" definidos como normais (Lovison et al., 2020).

Nesse sentido, a comunidade LGBTQI+, por questões do sentimento da não adequação do gênero ao sexo biológico (sistema sexo/gênero) ou à identidade heteronormativa (que a sociedade historicamente impõe), tem seus direitos humanos básicos limitados, agredidos, o que muitas vezes, os expõe a situações de vulnerabilidade social, econômica, de oportunidades e, igualmente, de acesso à instituições de saúde (Peres, 2011).

Nos estudos de Franklin et al (2016) tem-se tanto a carência de informações acerca das necessidades em saúde da população homossexual quanto insipiência na habilitação acadêmica partindo dos trabalhadores em saúde. A partir desta questão, Ferreira (2018) refere uma limitação da atuação do/a enfermeiro/a perante processos de educação em saúde e educação permanente com as equipes de trabalho, sendo, em muitos serviços, centrada em etapas como a aplicação de terapias hormonais.

Também vale destacar que a garantia de uso do nome social nos ambientes assistenciais do Sistema Único de Saúde, quanto assim solicitado pelos usuários, é uma forma de assumir o caráter respeitoso sobre a expressão de gênero dos indivíduos, assim como, o respeito vindo dos profissionais. Fatalmente ocorrem falhas nessa garantia, o que além de ferir preceitos legais, representam direta ou indiretamente desrespeito, discriminação e desconsideração à pessoa assistida; ao passo que a aplicação essa medida sem dúvida proporciona a oferta de uma assistência que obedece aos princípios do SUS, previstos na Lei n ${ }^{\circ} 8.080 / 1990$, capítulo II, Artigo $7^{\circ}$ (Brasil, 2013).

\section{Categoria 2- A assistência de enfermagem perante as políticas voltadas ao público LGBTQI+}

A regulamentação da Política Nacional de Saúde Integral da População Lésbica, Gay, Bissexual, Travesti e Transexual (PNSI-LGBT/ 2011), atende aos princípios constitucionais e define que é responsabilidade do SUS a promoção da 
saúde integral da população LGBT, eliminando a discriminação e o preconceito institucional e promovendo o acesso de travestis e transexuais aos serviços de saúde (Brasil, 2013).

As principais políticas são a Formulação do Brasil sem Homofobia: Programa de Combate à Violência e à Discriminação contra GLTB (gays, lésbicas, transgênero e bissexuais) e de Promoção da Cidadania Homossexual; Plano Nacional de Promoção da Cidadania e Direitos Humanos de LGBT (PNPCDH-LGBT); Programa Nacional de Direitos Humanos (PNDH); Coordenadoria Nacional de Promoção dos direitos de LGBT e a implantação do Conselho Nacional LGBT (Mello, 2012).

O Ministério da Saúde busca ampliar a questão das ações de intervenções de saúde à pessoas LGBTQI+ perpassando pelos níveis de complexidade, incluise, na Atenção Básica.Cite o oexemplo de 2014, onde se lançou as campanhas focadsa na população LGBTQI+, em conjunto com as Secretarias de Direitos Humanos (SDH) e de Políticas para as Mulheres (SPM), ganhando visibilidade através das mídias e materiais explicativos como o objetivo de sensibilizar sobre a saúde dos cidadãos LGBTQI+ (Garcia et al., 2016).

À enfermagem, cabe um papel relevante de acolhimento nas redes de atenção em saúde, bem como, o dever de atuar na aplicação integral das políticas públicas, na informação às usuárias da saúde e na construção de novas ações que auxiliem na eliminação da discriminação e em prol do direito de todos ao acesso humanizado e integral em saúde, ponderando as singularidades e necessidades individuais (Lovison et al., 2020).

Vale ressaltar que a enfermagem tem papel fundamental, no sentido de se apropriar dos conhecimentos necessários para a prestação de cuidados específicos e qualificados ao público LGBTQI+, uma vez que muitas vezes há seu afastamento dos serviços de saúde, em especial por não se sentirem acolhidos e não sentirem que as próprias demandas são efetivadas (Santos et al., 2020).

Diante dessas políticas, a enfermagem abrange o acolhimento qualificado, nos serviços especializados, na educação em saúde e em serviço e, sobretudo, em orientar corretamente o usuário LGBTQI+ quanto aos seus direitos, deveres e integralidade assistencial previstos no âmbito do SUS. Além disso, o enfermeiro deve manter uma postura reflexiva frente aos padrões heterossexuais socialmente estabelecidos, ajudando a prevenir e repelir ocorrências de preconceito e discriminação sobre esses usuários e oferecer-lhes uma assistência humanizada e holística, buscando alcançar suas necessidades de cuidados especificas. Para isso, é fundamental estar capacitado para atender e acolher adequadamente, pois em muitos casos as unidades de saúde, que são as portas de entrada ao serviço para esse usuário, carecem de profissionais habilitados e conscientes de seu papel na disseminação de uma conduta ética, respeitosa, humanizada e qualificada para o público LGBTQI+ (Rolim, 2016).

\section{Discussões}

A categoria 1, evidencia questões relacionadas ao acesso das pessoas transexuais aos serviços de saúde, dentre as quais, as principais dificuldades encontradas foram associadas ao preconceito e à discriminação, que ocorrem de maneira explícita ou implícita, desde a não utilização do nome social até emprego de expressões verbais ou corporais desrespeitosas (Roncon et al., 2020).

$\mathrm{O}$ atendimento discriminatório e as condutas constrangedoras estão entre as principais causas das travestis e transexuais se afastarem dos serviços de saúde, se automedicarem e não adotarem cuidados preventivos, o que propícia o surgimento e convivência com variados tipos de agravos a saúde. A negação aos direitos do público LGBTQI+ nos serviços de saúde está dentre os preconceitos experimentados por estes, podendo sujeitar a quadros graves, como depressão, estresse, estados de pânico e até mesmo suicídio (Lovison et al., 2020; Brasil, 2013).

Desta forma, percebe-se o quanto é necessário trabalhar a prevenção e a promoção à saúde dessa população, com o propósito de diminuir os agravos e assegurar os direitos de saúde, sexuais, reprodutivos, os quais dizem respeito à igualdade e 
à liberdade no exercício da sexualidade, o que significa tratar a sexualidade como uma dimensão de cidadania e da vida em uma sociedade democrática (Cabral et al., 2019).

Outro ponto relevante diz respeito a utização do nome social no momento em que se procura atendimento nos serviços de saúde, ao qual Coelho (2017) expõe que a falha no direito ao uso e respeito deste nome escolhido pelo paciente, o que se configura como violência, pois gera sofrimento e leva ao afastamento dessas pessoas dos atendimentos à saúde e viola seus direitos previstos pelos SUS. Assim, ressalta-se a importância de reconhecer, compreender e respeitar a identidade de gênero e todos os fatores que contribuem para o usuário se sentir acolhido e confortável no momento de usufruir dos serviços e de seus direitos em saúde.

Ressalta-se, ainda que é fundamental promover o acolhimento nos serviços de saúde, pois se trata de um método pensado e implementado a fim de auxiliar namelhora dos sistemas assistenciais, de maneira que possibilite aos usuários o acesso a um atendimento justo e pautado na integralidade, universalidade e equidade, com intuito de escutar e atender às necessidades de cuidados. Para tanto, é preciso avançar na estruturação do padrão de assistência à saúde da população LGBTQI+, superando as amarras socioculturais e as limitações do próprio do SUS (Santos et al., 2020).

A categoria 2, ressalta que a Política Nacional de Saúde voltada para o público LGBTQI+, inicialmente implementada em 2011, faz referência aos efeitos danosos da discriminação e exclusão. Por isso são necessárias novas abordagens sobre a temática, pois ainda existem desafios para a sua implementação. Nos estudos disponíveis na literatura científica brasileira, foi notada a grande importância de se melhorar as habilidades e competências dos profissionais para promover os cuidados de saúde ocorram de maneira mais equitativa e holística (Roncon et al., 2020).

Uma das principais dificuldades que a população em questão encontra ao procurar pelos serviços de saúde é a carência do conhecimento dos profissionais para lidar com o público, principalmente na área da ginecologia. Talvez pela limitação das informações acerca as práticas sexuais e outras formas de relacionamento nesse âmbito, o que indiretamente revela falhas na formação e/ou até ausência da capacitação profissional. Grandes são as adversidades para se promover a saúde integral do grupo LGBTQI+, a fim de eliminar a discriminação e o preconceito institucional, e assim contribuir para reduzir as desigualdades e a consolidação do SUS, pois é visível a necessidade de qualificação dos profissionais atuantes (Querino et al., 2017).

A equipe de enfermagem é responsável por atuar na pesquisa, educação em saúde e assistência direta aos usuários do SUS, e encarregado pela disseminação e implementação das políticas nacionais de saúde integral. As intervenções desenvolvidas por estes profissionais são de extrema importância visando à promoção da saúde, prevenção de doenças e reabilitação de situações de risco à saúde, muitas vezes contribuindo também em questões de amparo familiar e social. Cabe destacar que, a maior procura da população LGBTQI+ nas UBS ocorre na demanda espontânea, porém, surge aí uma oportunidade de acolhimento, divulgação e inclusão deste grupo em outros programas de saúde ofertados pelo SUS. Nesse sentido, o enfermeiro e a equipe multidisciplinar devem ter a percepção de realizar um bom acolhimento e promover o cuidado apoiado as diretrizes da Política LGBTQI+ (Garcia et al., 2016).

Nessa perspectiva, faz-se de grande importância que os princípios do SUS, sejam executados e transformem-se em políticas públicas que visem enfrentar as consequências da homofobia e da heteronormatividade ou continuarão existindo barreiras que impedem o acesso dessa população aos serviços de saúde (Melo et al., 2011).

\section{Conclusão}

O estudo demonstrou que para avançar na qualidade da assistência à população LGBTQI+ é preciso reconhecer as iniquidades no acesso aos serviços de saúde e os comportamentos discriminatórios que muitas vezes partem dos próprios 
trabalhadores da área, durante a assistência. É necessário valorizar questões específicas de saúde e singulares desse grupo, pois suas problemáticas de saúde emergem muitas vezes, com inexistência dos cuidados efetivos e adequados às suas demandas.

O estudo ainda evidenciou que o enfermeiro deve ter uma visão holística sobre o cuidado aos indivíduos, permitindo a identificação de fatores de risco que podem desenvolver agravos à saúde. Os profissionais de saúde deparam-se com certa dificuldade, no atendimento dessa clientela e por vezes não detêm qualificação suficiente para lidar com situações conflitantes voltadas a esse grupo, considerando a expressão de gênero e a sexualidade.

Portanto, o estudo aponta que a maior contribuição da enfermagem para a comunidade LGBTQI+ é a certeza de uma assistência humanizada em toda a cadeia assistencial, respeitando suas diferenças, ainda que não aceitando, mas tornandoalicerce para o cuidado integral, qualificado e humanizado.

A pesquisa demonstra que é importante garanti-los o acesso aos serviços de saúde, e o direito ao uso do nome social no SUS, aos cuidados à saúde em especial, no que se refere ao processo transexualizador e dar subsídio aos trabalhadores e profissionais para prestar atendimento qualificado.

Acredita-se que ao produzir e disseminar conhecimento sobre o tema, informar e sensibilizar a sociedade, bem como, os profissionais de saúde e gestores do SUS acerca das garantias de acesso ao atendimento, considerando as especificidades de saúde dessa população, possibilita-se avançar a um atendimento mais qualificado e humanizado.

A partir dos resultados desta pesquisa, é possível vislumbrar novas estratégias para estudos futuros do ponto de vista da gestão, para tornar os serviços de saúde ambientes mais inclusivos e desta forma combater as iniquidades no acesso à saúde para esse grupo social.

\section{Referências}

Botelho, L. L. R., Cunha, C. C. de A. \& Macedo, M. (2011). O método da revisão integrativa nos estudos organizacionais. Gestão e Sociedade - Belo Horizonte, 5(11), 121-136.

Brasil. (2013). Ministério da Saúde. Secretaria de Gestão Estratégica e Participativa. Departamento de Apoio à Gestão Participativa. Política Nacional de Saúde Integral de Lésbicas, Gays, Bissexuais, Travestis e Transexuais. Brasília: Ministério da Saúde.

Cabral, K. T. F. et al. (2019). Assistência de enfermagem às mulheres lésbicas e bissexuais. Revista de Enfermagem UFPE on line, $13(1)$, 79.

Cardoso, M. R. \& Ferro, L. F. (2012). Saúde e População LGBT: Demandas e Especificidades em Questão. Revista de Psicologia: ciência e profissão, 3(32), 552-63.

Coelho, A. A. et al. (2017). Uso do nome social no Sistema Único de Saúde: elementos para o debate sobre a assistência prestada a travestis e transexuais. Physis Revista de Saúde Coletiva, 27(3).

Dourado, I. et al. (2017). Construindo pontes: a prática da interdisciplinaridade. Estudo PopTrans: um estudo com travestis e mulheres transexuais em Salvador, Bahia, Brasil. Cad. Saúde Pública, 32(9), e00180415.

Franklin, T. A. et al. (2016). Bioética da proteção na acessibilidade à saúde de lésbicas, gays, bissexuais, travestis e transexuais. Rev enferm UFPE, 10(9), 3483-8.

Ferreira, B. O. et al. (2018). Vivências de travestis no acesso ao SUS. Physis: Revista de Saúde Coletiva, 27(4), 1.023-1.038.

Garcia, F. G., Batista, D. S., Santos, M. C. (2016). A política nacional de saúde integral LGBT no Sistema Único de Saúde (SUS), Brasil. Rev Cient Inst Ideia, $2,1-18$.

Jesus, J. G. de. (2012). Guia técnico sobre pessoas transexuais, travestis e demais transgêneros, para formadores de opinião. Orientações sobre identidade de gênero: Conceitos e termos. (2a ed.).

Lima, T. F. da S. et al. (2021). Variáveis climáticas e sua relação com doenças de origem infecciosa: Uma revisão integrativa. Research, Society and Development, 10(2), e7910212126. https://doi.org/10.33448/rsd-v10i2.12126

Lovison, R. et al. (2020). Travestis e transexuais: despindo as percepções acerca do acesso e assistência em saúde. Enfermagem em Foco, 10(5), 167-172.

Mello, L. et al. (2011). Políticas de saúde para lésbicas, gays, bissexuais, travestis e transexuais no Brasil: em busca de universalidade, integralidade e equidade. Revista Latinoamericana Sexualidad, Salud y Sociedad, 9, 7-28.

Mello, L., Walderes, B. \& Maroja, D. (2012). Políticas públicas para a população LGBT no Brasil: Notas sobre alcances e possibilidades). Revista Cadernos Pagu, 39(39), 403- 429. 
Research, Society and Development, v. 10, n. 5, e26510514590, 2021

(CC BY 4.0) | ISSN 2525-3409 | DOI: http://dx.doi.org/10.33448/rsd-v10i5.14590

Minayo, M. C. de S. (2017). Cientificidade, generalização e divulgação de estudos qualitativos. Ciência \& Saúde Coletiva. 22(1),16-17.

Peres, W. S. (2011). Dissidências Existenciais de Gênero: resistências e enfrentamentos ao biopoder. Psicologia Política. 11(22), 261-277.

Pinto, J. J. et al. (2017). A medicalização e patologização na perspectiva das mulheres transexuais: acessibilidade ou exclusão social. Revista de Enfermagem UERJ, 25, 1-6.

Popadiuk, G. S., Oliveira, D. C. \& Signorelli, M. C. (2017). A Política Nacional de Saúde Integral de Lésbicas, Gays, Bissexuais e Transgêneros (LGBT) e o acesso ao Processo Transexualizador no Sistema Único de Saúde (SUS): avanços e desafios. Ciência \& Saúde Coletiva [online], 22(5), 1509-1520.

Querino, M. dos S. et al. (2017). Ações da equipe de enfermagem na implementação da política de lésbicas, gays, bissexuais, travestis e transexuais- revisão de literatura. Rev. Cient. Sena Aires, 6(1).

Rolim, A. G. F; et al. (2016). A Realidade de um Serviço de Média Complexidade Para o Público LGBT, voltado para Atenção á Saúde Sexual e Reprodutiva da População: Do Ideal ao Real. Revista de Extensão da Univasf, 4(2),01-09.

Rocon, P. C. et al. (2020). Acesso à saúde pela população trans no brasil: nas entrelinhas da revisão integrativa. Trabalho, Educação e Saúde, $18(1)$, e0023469.

Santos, L. E. S. dos et al. (2020). Access to the Unified Health System in the perspective of male homosexuals. Revista Brasileira de Enfermagem, 73(2), 1-8.

Santos, A. L. M. (2016). O estado da arte sobre as barreiras no acesso à saúde para travestis e transexuais. Monografia (Graduação). Faculdade de Medicina da Universidade Federal da Bahia. Salvador.

Teixeira, E. et al. (2014). RIL métodos de revisão. Revista de Enfermagem da UFPI, 2(5), 3. 